\title{
Study on Application of Novachip Ultra-thin Layer
}

\author{
Ruihua Yang ${ }^{1,}{ }^{*}$, Chao Zhang ${ }^{2}$, Qiancheng Zhou $^{3}$, and Yinghui Liang ${ }^{1}$ \\ ${ }^{1}$ Shanghai Urban Construction Vocational College, Shanghai 200438, China \\ ${ }^{2}$ Fujian Provincial Expressway Technology Consulting Co., Ltd., Fuzhou 350108, China \\ ${ }^{3}$ Shanghai Technical Institute of Electronics \& Information, Shanghai 201400, China
}

\begin{abstract}
Based on the Novachip ultra-thin layer project in the expressway, the material characteristics, mixture design and road performance of Novachip asphalt mixture are introduced. The application effect of Novachip ultra-thin layer was observed. The results show that Novachip ultra-thin layer has no obvious effect on improving the smoothness of the original road surface. Novachip ultra-thin layer has obvious effect on improving the rutting, and has a good anti-skid performance.
\end{abstract}

\section{Introduction}

Novachip ultra-thin layer is an ultra-thin layer of asphalt mixture with a thickness of $10 \mathrm{~mm} \sim 25 \mathrm{~mm}$. It originated in France in 1986 and has been widely used in European and American countries. In China, Novachip Ultra-thin layer technology was applied relatively late, and the experimental section of Guangshao expressway was first laid in 2003. In recent years, some relevant units have carried out some researches on material composition,mix ratio design and construction technology, but compared with foreign countries, there are few practical engineering reference cases, and there is a lack of systematic and indepth analysis and research on the application.

This paper makes a comprehensive study on the application of Novachip ultra-thin layer on a highway in south China, which has important guiding significance for engineering design, construction and quality control.

\section{Interlayer binder of Novachip ultra- thin layer}

High viscosity modified emulsified asphalt is adopted as Novachip ultra-thin interlayer bonding material. Its main function is to firmly bond the ultra-thin with the original road surface to form a whole, and bear the effect of temperature stress and driving load together. Therefore, the binder is required to have a good adhesive performance and prevent the diseases of asphalt pavement, such as the pushing, upheaval or bleeding. The test results of modified emulsified asphalt are shown in Table1.

Table1. Test results of modified emulsified asphalt

\begin{tabular}{|c|c|c|}
\hline \multicolumn{2}{|r|}{ Tests } & Test results \\
\hline \multicolumn{2}{|r|}{ Charge } & cationic \\
\hline \multicolumn{2}{|c|}{ The amount remaining on screen $(1.18 \mathrm{~mm}), \%$} & 0.0 \\
\hline \multicolumn{2}{|c|}{ Standard viscosity C25. 3, s } & 20 \\
\hline \multirow{4}{*}{ Evaporated residue } & Residue content, $\%$ & 66.9 \\
\hline & Penetration, $25^{\circ} \mathrm{C}, 0.1 \mathrm{~mm}$ & 113 \\
\hline & Softening point, ${ }^{\circ} \mathrm{C}$ & 43.5 \\
\hline & $\operatorname{Ductility}\left(5^{\circ} \mathrm{C}, 5 \mathrm{~cm} / \mathrm{min}, \mathrm{cm}\right)$ & 35 \\
\hline \multirow{2}{*}{ Storage stability } & $1 \mathrm{~d}, \%$ & 0.6 \\
\hline & $5 \mathrm{~d}, \%$ & 0.4 \\
\hline
\end{tabular}

\footnotetext{
* Corresponding author E-mail: yangruihua@succ.edu.cn
} 


\section{Asphalt mixture design of Novachip ultra-thin layer}

\subsection{Raw materials}

The aggregate adopts basalt ore, and the relevant coarse aggregate and fine aggregate technical indexes meet the requirements of technical specifications. The asphalt adopt Shell's Novabinder Polymer modified asphalt. All the test indexes meet the Technical Specification for Highway Asphalt Pavement Construction (JTG F402004) . The test results of Novabinder Polymer modified asphalt are shown in Table2.

Table2. Test results of Novabinder Polymer modified asphalt

\begin{tabular}{|c|c|c|}
\hline Tests & unit & Test results \\
\hline $\begin{array}{c}\text { Penetration } \\
\left(25^{\circ} \mathrm{C}, 5 \mathrm{~s}, 100 \mathrm{~g}\right)\end{array}$ & $0.1 \mathrm{~mm}$ & 57 \\
\hline $\begin{array}{c}\text { Softening Point } \\
T_{R \& B}\end{array}$ & ${ }^{\circ} \mathrm{C}$ & 88.5 \\
\hline $\begin{array}{c}\text { Ductility } \\
\left(5^{\circ} \mathrm{C}, 5 \mathrm{~cm}\right)\end{array}$ & $\mathrm{cm}$ & 23 \\
\hline Density $\left(25^{\circ} \mathrm{C}\right)$ & $\mathrm{g} / \mathrm{cm} 3$ & 1.029 \\
\hline Segregation (48h) & ${ }^{\circ} \mathrm{C}$ & -0.9 \\
\hline Dynamic viscosity $\left(60^{\circ} \mathrm{C}\right)$ & $\mathrm{Pa} \cdot \mathrm{s}$ & 40000 \\
\hline Kinematical viscosity $\left(135^{\circ} \mathrm{C}\right)$ & $\mathrm{Pa} \cdot \mathrm{s}$ & 0.98 \\
\hline Elastic recovery $\left(25^{\circ} \mathrm{C}\right)$ & $\%$ & 97 \\
\hline \multicolumn{3}{|c|}{ RTFOT aging residue } \\
\hline Mass loss & $\%$ & 0.391 \\
\hline Penetration ratio $\left(25^{\circ} \mathrm{C}\right)$ & $\%$ & 80 \\
\hline $\begin{array}{c}\text { Ductility } \\
\left(5^{\circ} \mathrm{C}, 5 \mathrm{~cm}\right)\end{array}$ & $\mathrm{cm}$ & 18 \\
\hline
\end{tabular}

The performance of Novabinder Polymer modified asphalt binder is close to that of the I-D SBS modified asphalt in the Technical Specification for Highway Asphalt Pavement Construction (JTG F40-2004), according to the data of the three indexes of penetration, softening point and ductility. It has obvious characteristics of high viscosity and high elasticity and it has good ductility and low temperature toughness.

\subsection{Design of mix proportion}

Novachip ultra-thin layer mixture is a typical gap gradation. The composition proportion of different sizes mineral are shown in Table 3. The composite gradation is shown in table4.

Table3. Mineral composition of different sizes

\begin{tabular}{|c|c|}
\hline Size $/ \mathrm{mm}$ & Proportion/\% \\
\hline $6-11$ & 72 \\
\hline $3-6$ & 5 \\
\hline $0-3$ & 19.5 \\
\hline Minral powder & 3.5 \\
\hline
\end{tabular}

Table4. Composite gradation of asphalt mixutr

\begin{tabular}{|c|c|}
\hline Screen size $/ \mathrm{mm}$ & Passing percent $/ \%$ \\
\hline 16 & 100 \\
\hline 13.2 & 100 \\
\hline 9.5 & 99 \\
\hline 4.75 & 29.9 \\
\hline 2.36 & 21.8 \\
\hline 1.18 & 16.8 \\
\hline 0.6 & 12.3 \\
\hline 0.3 & 8.5 \\
\hline 0.15 & 6.8 \\
\hline 0.075 & 5.5 \\
\hline
\end{tabular}

From the perspective of its grading composition, the maximum particle size of Novachip is $9.5 \mathrm{~mm}$, and the grading composition is obviously coarse, indicating that Novachip is a skeleton pervious material type. The permeable thin layer has good construction performance and is easy to spread evenly. According to the design test method of Marshall material of asphalt mixture, doublesided compaction was used for 50 times, and the optimal asphalt consumption was $4.7 \%$. The technical index values of Marshall test under the optimal bitumen dosage are shown in Table5. 
The void ratio of Novachip asphalt mixture was $15.4 \%$, indicating that the Novachip thin layer has the function of internal drainage in the thin layer. The loss rate was less than $10 \%$ in the Cantabro test, which indicated that the mixture of the thin coating surface had better cohesion and could resist the related diseases such as dropping particles. The small Run-off loss indicates that the mixture can realize the stability of asphalt in the thin coating surface, and under the condition of the quality control in place, the oil flooding and other related diseases will not occur easily.

Table5. Marshall test results

\begin{tabular}{|l|l|l|l|}
\hline Tests & unit & $\begin{array}{l}\text { Technical } \\
\text { equirements }\end{array}$ & Test results \\
\hline number of compaction $\quad$ (both sides $)$ & times & 50 & 50 \\
\hline Compaction temperature & ${ }^{\circ} \mathrm{C}$ & Measured & 165 \\
\hline VV & $\%$ & Measured & 15.4 \\
\hline VMA & $\%$ & Measured & 24.5 \\
\hline MS & $\mathrm{kN}$ & $\geqq 8$ & 11.90 \\
\hline FL & $\mathrm{mm}$ & $1.5 \sim 4$ & 3.61 \\
\hline VFA & $\%$ & Measured & - \\
\hline asphalt film thickness & $\mu \mathrm{m}$ & Measured & 9.08 \\
\hline Cantabro test, $\%$ & $\%$ & $\leq 10$ & 8.5 \\
\hline run-off loss & $\%$ & $\leq 0.2$ & 0.08 \\
\hline
\end{tabular}

\section{Asphalt mixture performance test of Novachip Ultra-thin layer}

Referring to the performance verification indexes and test methods of the asphalt mixture, the performance tests of Novachip ultra-thin layer asphalt mixture at high temperature, low temperature and water damage resistance were carried out.

\subsection{High temperature stability test}

The high-temperature stability of asphalt mixture refers to its ability to withstand the action of load and maintain the stability of structure and performance without affecting its service performance under high temperature conditions. In this study, the dynamic stability of asphalt mixture wheel tracking test is used as the evaluation index of hightemperature stability. The test results showed that the dynamic stability of Novachip ultra-thin layer asphalt mixture rut test was more than 6000 times $/ \mathrm{mm}$ in three parallel tests. The results of dynamic stability meet the requirements of the specification. Novachip ultra-thin layer asphalt mixture has good rutting resistance at high temperature.

\subsection{Water stability test}

The water damage of asphalt pavement is one of the important factors in the early failure of asphalt pavement. In this study, AASHTO T283 and freeze-thaw splitting tests were used to evaluate the water stability of asphalt mixture. The results of AASHTO T283 tests showed that the immersion residual stability of the specimens was $87.4 \%$, which was higher than $85 \%$ as required by the specification. The results of freeze-thaw splitting tests showed that the intensity ratio of frozen and melted of asphalt mixture is $88.7 \%$, which is more than $80 \%$ as required by the specification. Both experiments show that the water stability of Novachip ultra-thin layer asphalt mixture is good.

\subsection{Low temperature cracking resistance test}

Low temperature cracking of asphalt pavement is harmful and seriously affects the service life of the road. In this study, the low temperature cracking resistance of asphalt mixture was evaluated by the low temperature bending test at $-10^{\circ} \mathrm{C}$. The maximum bending strain during low temperature bending failure is used as the index to evaluate low temperature cracking resistance. The maximum bending strain at low temperature is $4326 \mu \varepsilon$, higher than $2500 \mu \varepsilon$ as required by the standard.

\section{Evaluation of Novachip ultra-thin layer detection}

The test section of Novachip ultra-thin layer was paved. Based on the historical and technical data of the road surface in the test section, the road performance indexes of RQI, RDI and SRI in the test section were collected by the road surface multifunctional inspection vehicle before the construction of the test road. After the completion of construction, the RQI, RDI and SRI of the test section were detected. Through the change of these three indexes, the effect of improving the road surface with thin layer is 
evaluated. The detection data of RQI, RDI and SRI before and after the treatment of Novachip ultra-thin layer are shown in Table 6.

The test results show that after using Novachip ultrathin layer, the smoothness, rutting and anti-skid performance of the road surface are improved to different degrees. After the construction of Novachip ultra-thin layer, the flatness index IRI has a slight improvement, which is mainly to maintain the original pavement flatness performance level. The rutting depth decreased from $4.5 \mathrm{~mm}$ to $2.3 \mathrm{~mm}$. The rutting depth decreased by $49 \%$. Novachip ultra-thin layers can significantly improve road rutting. Sliding resistance transverse force coefficient SFC increased from 57.7 to 78 . The lateral force coefficient SFC increased by $35 \%$. Novachip ultra-thin layer can obviously improve the anti-skid performance of road surface.

Table6. The change of road technical condition index before and after using Novachip ultra-thin layer

\begin{tabular}{|c|c|c|c|}
\hline \multicolumn{2}{|c|}{ detection period } & before using & after using \\
\hline \multirow{3}{*}{ Detection value } & IRI & 1.4 & 1 \\
\cline { 2 - 4 } & RD & 4.5 & 2.3 \\
\cline { 2 - 4 } & SFC & 57.7 & 78 \\
\hline \multirow{3}{*}{$\begin{array}{c}\text { Pavement technical } \\
\text { condition index }\end{array}$} & RQI & 93.7 & 95.2 \\
\cline { 2 - 4 } & RDI & 91 & 95.4 \\
\cline { 2 - 4 } & SRI & 95.8 & 99.5 \\
\hline
\end{tabular}

\section{Conclusion}

The application of Novachip ultra-thin layer in preventive maintenance of expressway asphalt pavement was studied. The following conclusions are drawn.

(1) The asphalt binder used for the Nocachip ultra-thin layer has obvious characteristics of high viscosity and high elasticity.

(2) Novachip ultrathin layer asphalt mixture is a typical fault gradation. The maximum diameter of asphalt mixture is $9.5 \mathrm{~mm}$, and the grading composition is obviously coarse. The void ratio of asphalt mixture is $15.4 \%$, with internal drainage function of thin layer, and it is the framework pervious material type. Laboratory tests show that it has good high temperature stability, low temperature crack resistance and water stability.

(3) Novachip ultra-thin layer as a preventive maintenance measure, has no obvious effect on improving the smoothness of the original road surface, but has obvious effect on improving the rutting, and has a good anti-skid performance after use.

\section{Reference}

1. Liu Wu, Deng Jun-shuang, Effectiveness Analysis of Various Easy- Compact Ultra-Thin Overlay Treatments, Journal of China \& Foreign Highway, 39 (3), 64, (2019)

2. Song Yang, Study on application of Novachip ultrathin wear layer in expressway preventive maintenance, SouthChina University of Technology, Guangzhou, China, (2016)

3. Zhang YiQun, Nan Binzhang, Yuan Bin, Novachip
Ultra-thin Mask Mixing ratio Design Analysis, Journal of highway and Transportation Research and Development,11(11), 116, (2015)

4. Qian Puzhou, Chao Qingxia, Wei Dinbang, Zhang Guohong, Novachip Ultrathin layer Material performance Study, Highway, Vol.61, 233, (2016)

5. Wang Shuxin, Application of ultra-thin layer in Qingyin Highway Maintenance Project, Journal of highway and Transportation Research and Development, 4(11), 28, (2015) 